\title{
Field Evaluation of Discretized Model Setups for the Storm Water Management Model
}

\author{
Robson L. Pachaly, ${ }^{1}$ Jose G. Vasconcelos, ${ }^{2}$ Daniel Allasia ${ }^{1}$ and Bruna Minetto \\ ${ }^{1}$ Federal University of Santa Maria, Rio Grande do Sul, Brazil; ${ }^{2}$ Auburn University, Auburn, Alabama.
}

\begin{abstract}
The Stormwater Management Model (SWMM) is a hydrologic-hydraulic model often used to simulate water flows in urban drainage systems and changes in water quality. The unsteady flow hydraulic solver in SWMM solves mass and momentum conservation equations for the entire conduit length, and mass is conserved at each junction. This link-node approach used by SWMM does not allow for discretization (i.e. intermediate calculation points) between consecutive junctions, which is adequate in gradual filling scenarios with appropriate calibration and suitable selection of routing time steps. However, because there are more rapid filling scenarios that are associated with intense rain events, the link-node solution approach will affect the accuracy of the hydraulic calculations. This work presents the results of a field investigation in which predetermined volumes of water were suddenly released into a physical stormwater collection system. Level loggers were installed to measure flow depth and outflow rates in these tests. The results were compared with SWMM modeling results obtained by the link-node approach using alternative SWMM model setups which included additional intermediate discretization. The goal was to assess the potential benefits of SWMM discretization in the context of rapidly filling collection systems.
\end{abstract}

\section{Introduction}

The Storm Water Management Model (SWMM) is a dynamic hydrologic-hydraulic model often used in the context of urban drainage (Rossman 2015). It can be used to simulate runoff quantity and quality for single event or continuous hydrologic modeling (e.g. Tsihrintzis and Hamid 1998; Camorani et al. 2005; Temprano et al. 2006; Chow et al. 2012; Qin et al. 2013). The model calculates the runoff generated by subcatchments, routes it through the collection system and computes variables such as flow rate, flow depth and water quality parameters. SWMM is a model widely used worldwide (Obropta and Kardos 2007; Niazi et al. 2017) and its applications include planning, analysis, design and diagnosis of stormwater drainage systems and combined and sanitary sewers systems (Rossman 2015).

SWMM allows flows to be routed through a wide variety of conduits, including pipes, channels, storage and treatment devices, pumps, and regulators. The model represents collections of system components using various types of nodes (e.g. junctions, storage units and outlets) and various types of conduits, referred to as links. SWMM's unsteady flow hydraulic solver is used to resolve the flow conditions in the network of links and nodes through one-dimensional equations. Saint-Venant equations are used to solve unsteady flows, both in subcritical and supercritical modes, whereas pressurized unsteady flows are solved with a set of mass and momentum equations (Rossman 2017).
The Saint-Venant equations are a system of partial differential equations that represent the conservation of mass and linear momentum in conduits (Sturm 2010) and apply mass conservation and energy equations to resolve flows in each junction. Alternatively, SWMM can introduce some simplifications in the solution of the mass and momentum equations to solve flows using the zero-inertia wave or kinematic wave approaches (Rossman 2017). The first simplification neglects local or convective acceleration terms in the momentum equation and is applicable when backwater effects are dominant and hydraulic jumps or bores are absent. The kinematic wave solution is even simpler but more restrictive and is only recommended for flow conditions involving steeper slopes and rough beds (Sturm 2010).

Intense rain events leading to rapid filling conditions of collection systems have the potential to cause problems such as pressurization of conduits, entrapment of air pockets within the pipes, pressure surges and even water hammer (Zhou et al. 2002; Guizani et al. 2006) independent of the system geometry. In such cases, the use of complete Saint-Venant equations is often necessary. However, the link-node solution method in SWMM does not use spatial discretization in conduits between two adjacent nodes and, because of that, the model does not represent highly dynamical changes well, particularly transitions to pressurized flow conditions (Ridgway and Kumpula 2007; Vasconcelos et al. 2018). High values of flow continuity error, the presence of numerical spikes or oscillations and other could be yielded by

Pachaly, Robson L., Jose G. Vasconcelos, Daniel Allasia and Bruna Minetto. 2019 "Field Evaluation of Discretized Model Setups for the Storm Water Management Model." Journal of Water Management Modeling 27: C463. doi: 10.14796/JWMM.C463.

() CHI 2019. www.chijournal.org ISSN 2292-6062. 
SWMM solution when such situations occur. Reducing or allowing a variable time step, lengthening short conduits, dampening or ignoring the inertial terms of the Saint-Venant equations, or reducing the head convergence tolerance are approaches to deal with those unrealistic results (Rossman 2015), although the accuracy could be impaired.

According to Popescu (2014), using small temporal and spatial discretizations when solving the Saint-Venant equations can lead to improvements in accuracy since the approximation error is small. Therefore, through careful selection of time step and artificial discretization of conduits, simulation results can be significantly improved in SWMM (Ridgway et al. 2007; Vasconcelos et al. 2018). However, the artificial spatial discretization in SWMM was only investigated in reduced scale experiments (Vasconcelos et al. 2018) or compared with other models (Ridgway et al. 2007), never in an existent and on service stormwater collection system.

Nowadays, there are many hydraulic models that rely on discretization in their formulations, including the Transient Analysis Program (TAP) by Applied Science (Ridgway et al. 2007), Model for Urban Sewers (MOUSE) by the Danish Hydraulic Institute (DHI 2017), among others. In these hydraulic models, the spatial discretization can be set automatically by the model when solving the flow in a network. However, in some, such as MOUSE (DHI 2017), the number of grid points can be specified by the user. Moreover, a modified version of the Saint-Venant equations can be used to handle both pressurized and free surface flows. Therefore, it is hypothesized that SWMM results can be improved through spatial discretization modeling.

The goal of this work is to assess the potential benefits of SWMM discretization, as well as different discretization strategies, in the context of rapid inflows into collection systems. To achieve this goal, field tests were conducted in which a predetermined water volume was suddenly released into a collection system, resulting in changes in riser water levels that were monitored by sensors. Different SWMM models were created to describe this filling process and modeling results were compared with field pressure head measurements.

\section{Methodology}

\subsection{Field Investigation}

The stormwater collection system used in this field investigation is located at the Federal University of Santa Maria (UFSM) in the city of Santa Maria, Rio Grande do Sul, Brazil. This system consists of 15 risers and 14 circular conduits, 6 of which are in the direct path of sudden inflow. The system design is shown in Figure 1.

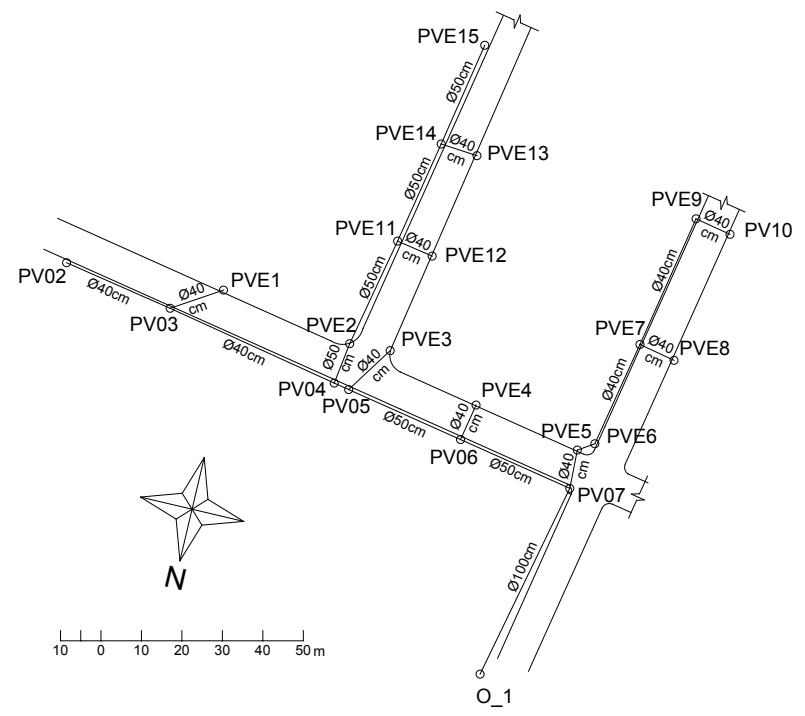

Figure 1 Collection system layout.

This collection system drains to an intermittent stream located at the northwest limit of the university campus which in turn discharges into the Lagoao do Ouro Creek. Prior to the field experiments the collection system was dry. The conditions of the system were not thoroughly inspected but it is safe to assume that its components are poorly maintained.

At the upstream riser, an artificial reservoir containing approximately $10 \mathrm{~m}^{3}$ water was created. At the system inlet (PV02), a $400 \mathrm{~mm}$ concrete conduit was blocked using a thick plastic mat secured with cables. Sudden removal of the cables led to the quick release of water, producing rapid inflow in the system.

During the system filling, the water levels at PV02 and PV07, 136 m apart, were monitored using HC-SR04 ultrasonic sensors built using the Arduino prototyping platform with accuracy of $3 \mathrm{~mm}$, range $2 \mathrm{~cm}-4 \mathrm{~m}$, and sampling frequency $1 \mathrm{~Hz}$ (Arduino 2018). The measurements of water levels obtained during the system filling were used to determine if the alternative modeling setup produced more reliable results when compared to the standard link-node approach.

\subsection{Numerical Investigation}

\section{General Simulation Options}

SWMM (release 5.1.012) dynamic wave routing was used to perform the simulations because it solves the complete Saint-Venant equations and yields more precise results than alternative solvers. However, a small time step was chosen to maintain the numerical stability and consequently large computational effort was required, mainly in the case of the discretized layouts. The routing time step selected was $0.001 \mathrm{~s}$. Smaller time steps did not improve the results significantly. When we used the time step recommended in SWMM-EXTRAN documentation (Roesner et al. 1988), given in Equation 1, continuity errors were large: 


$$
\Delta T=\frac{L}{\sqrt{g D}}
$$

where:

$$
\begin{aligned}
\Delta T & =\text { time step } \\
L & =\text { conduit length, } \\
g & =\text { gravity acceleration, and } \\
D & =\text { conduit diameter. }
\end{aligned}
$$

In dynamic wave modeling options, we decided to maintain the inertial terms at their full values under all conditions; the normal flow criteria chosen was the recommended slope and Froude number, and the main equation selected to compute friction losses during pressurized flow was the Hazen-Williams equation. The internally computed variable time step was disabled, so that the selected routing time step was maintained throughout the calculations.

When there are free surface flows, SWWM solves the Saint-Venant equations (Equations 2 and 3):

$$
\begin{aligned}
& \frac{\partial A}{\partial t}+\frac{\partial Q}{\partial x}=0 \\
& \frac{\partial Q}{\partial t}+\frac{\partial\left(Q^{2} / A\right)}{\partial x}+g A \frac{\partial H}{\partial x}+g A\left(S_{f}+h_{L}\right)=0
\end{aligned}
$$

Different equations (Equations 4 and 5) are used to solve flows in conduits in pressurized mode, in which a lumped inertia approach (Wylie and Streeter 1993) is used:

$$
\begin{aligned}
& Q=A_{f} V \\
& \frac{d Q}{d t}=-\left(\frac{g A}{L}\right)\left(\frac{\Delta H}{1+\Delta Q_{\text {friction }}+\Delta Q_{\text {losses }}}\right)
\end{aligned}
$$

where:

$A=$ cross-sectional area of the flow,

$Q=$ flow rate,

$H=$ hydraulic head of water in the conduit (elevation head plus any possible pressure head),

$S_{f}=$ friction slope,

$h_{L}=$ local energy loss per unit length of conduit,

$g=$ gravity acceleration,

$A_{f}=$ full pipe flow,

$\Delta_{t}=$ routing time step size,

$L=$ conduit length,

$V=$ average pipe flow velocity in full pipe conditions $\left(Q / A_{f}\right)$,

$\Delta Q_{\text {friction }}=$ a nondimensional term that increases with the friction losses along the conduit, and

$\Delta Q_{\text {losses }}=$ a nondimensional term that increases with the local losses along the conduit.

The simulation parameter Minimum Nodal Surface Area (MNSA), which represents the minimum plan area that is provided by a node, was changed to a small value of $0.01 \mathrm{~m}^{2}$. The default value for MNSA in SWMM is $1.167 \mathrm{~m}^{2}$, which corresponds to the plan area of $1.167 \mathrm{~m}^{2}\left(12.566 \mathrm{ft}^{2}\right)$ of a typical $1.2 \mathrm{~m}(4 \mathrm{ft})$ diameter riser. Modifying the MNSA value changes the storage provided by every node in SWMM, which has an impact on calculations particularly when using dummy nodes to create artificial discretization. Since the artificial nodes are not supposed to create extra storage in the modeling efforts, the intention was to keep this model parameter small.

The conduit modeling parameters were set to represent the physical collection system characteristics. The conduit shape was set up as circular having a Manning roughness of 0.017 (monolithic concrete with rough form). The entry and exit losses were computed only for conduits entering and exiting the physical risers, with a value of 0.5 .

As the observed field data were water levels, the system inflow should also be a water level to ensure more accurate modeling. To ensure this, the upstream junction (PV02) was converted to an outfall with no inflow with time series as the boundary condition. The invert elevation of PV02 was added to the water level measured at PV02 to create the water level time series. This water level time series was used as the boundary condition at PV02.

\section{Traditional Layout}

SWMM (EPA 2017), currently in version 5.1, has an unsteady flow equation solver based on the EXTRAN algorithm described by Roesner et al. (1988) and Rossman (2006), which uses a link-node discretization. The traditional SWMM system layout which represents the physical configuration is shown in Figure 2.

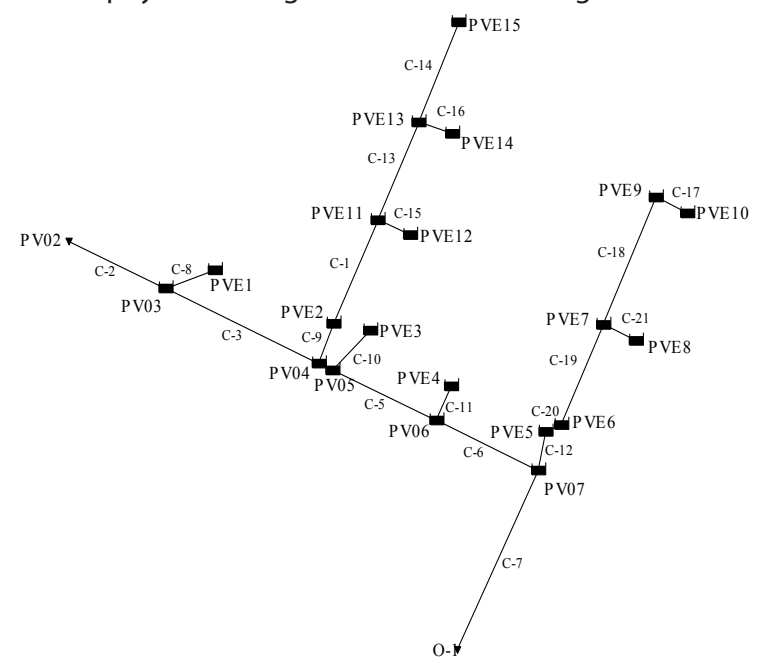

Figure 2 Traditional SWMM link-node configuration.

The drainage system in this study is relatively small, so riser storage should be included in the simulation for better results. Thus, storage units with areas matching the physical risers were used instead of junctions. In all simulated conditions the maximum depth of physical (or dummy) junctions was set to match the physical terrain elevation.

The flow routing algorithm used by SWMM does not use intra-conduit discretization between two adjacent nodes, which would be typical of more contemporary unsteady flow solvers. 
On the one hand the absence of intra-link discretization solutions significantly reduces computational effort, but on the other hand it can affect the ability of the model to accurately solve highly dynamic flow conditions associated with rapid fillings. Therefore, it is expected that adding artificial spatial discretization in links could improve SWMM accuracy to model highly dynamic conditions.

\section{Alternative Layout: Regular Interval (10 Dummy Junctions) Discretization}

This alternative setup was conceived to create an artificial spatial discretization in the network by placing 10 intermediate dummy junctions between two consecutive storage units, as originally shown in the first (traditional) approach, independent of the link length. The minimum distance between each dummy junction is $0.32 \mathrm{~m}$ (PV04-PV05) and the maximum distance is $4.63 \mathrm{~m}$ (PV07-O_1). This alternative SWMM layout, including a magnification in the PV04-PV03 stretch, is shown in Figure 3.

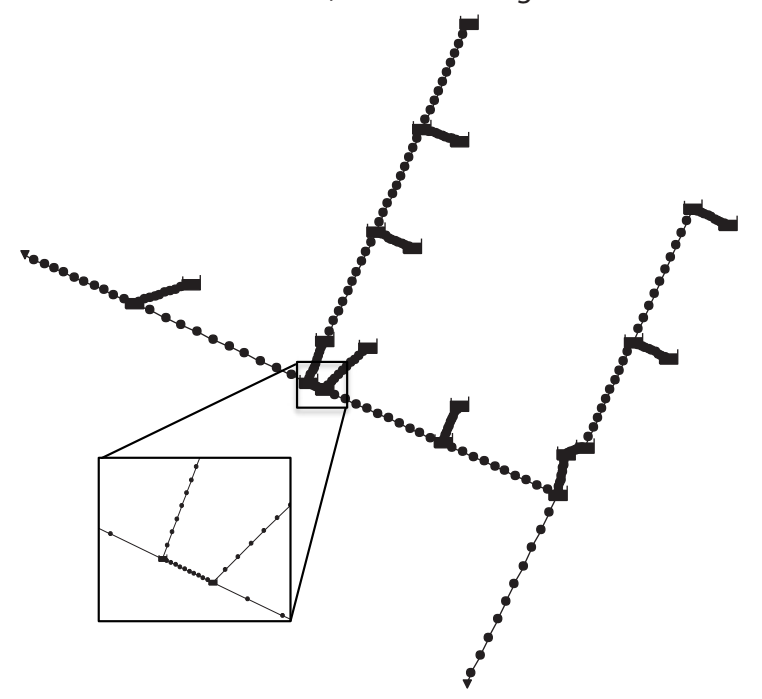

Figure 3 Alternative layout: Regular Interval (10 dummy junctions).

It is important to note that when artificial discretization is used the links generated by the new arrangement of dummy nodes maintain the same characteristics of the original link. In other words, the new links will inherit the original link roughness and the entry and exit losses will be accounted only in the first and last links connected to the physical risers.

\section{Alternative Layout: Fixed Interval (1 m-3 m) Discretization}

The second alternative layout was created by limiting the artificial spatial discretization between physical risers to a minimum distance of $1 \mathrm{~m}$ and a maximum of $3 \mathrm{~m}$. This procedure resulted in the minimum discretization length $1.01 \mathrm{~m}$ (PV03-PV04) and maximum 2.22 m (PV07-O_1) in order to obtain the required number of discretization intervals. The layout of this discretization and the magnification in the same location as the previous layout are shown in Figure 4.

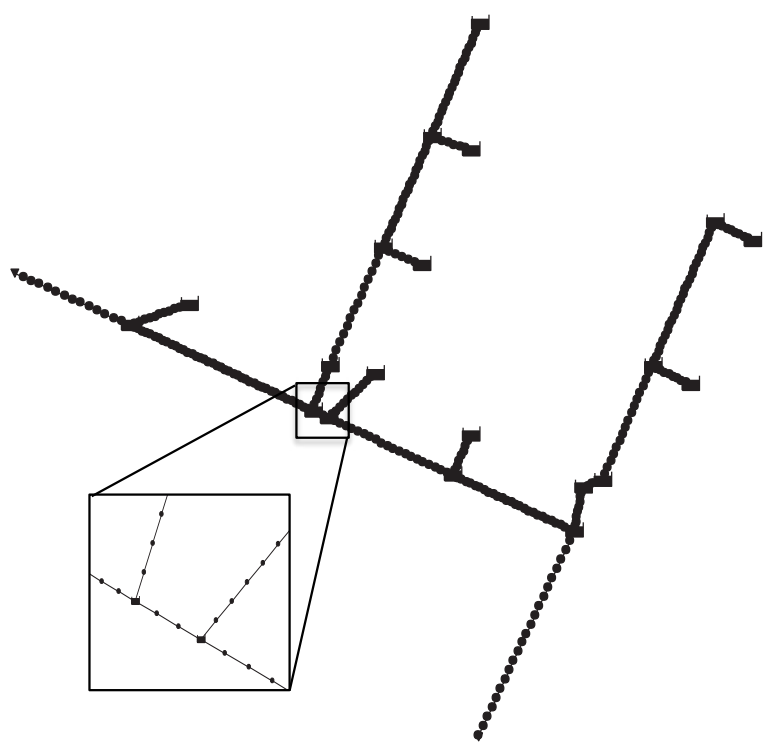

Figure 4 Alternative layout: Fixed Interval (1 m-3 m).

Alternative Layout: Diameter Based (10×) Discretization The last alternative layout was based on the link diameter. In other words, each link present in the system was divided by 10 times its own diameter. If necessary the division was rounded to an integer to get an exact number of discretization nodes. This approach resulted in a minimum distance between each dummy junction of $3.51 \mathrm{~m}$ (PVE3-PV05) and maximum $10.20 \mathrm{~m}$ (PV07-O_1). The layout of this system and the magnification are shown in Figure 5.

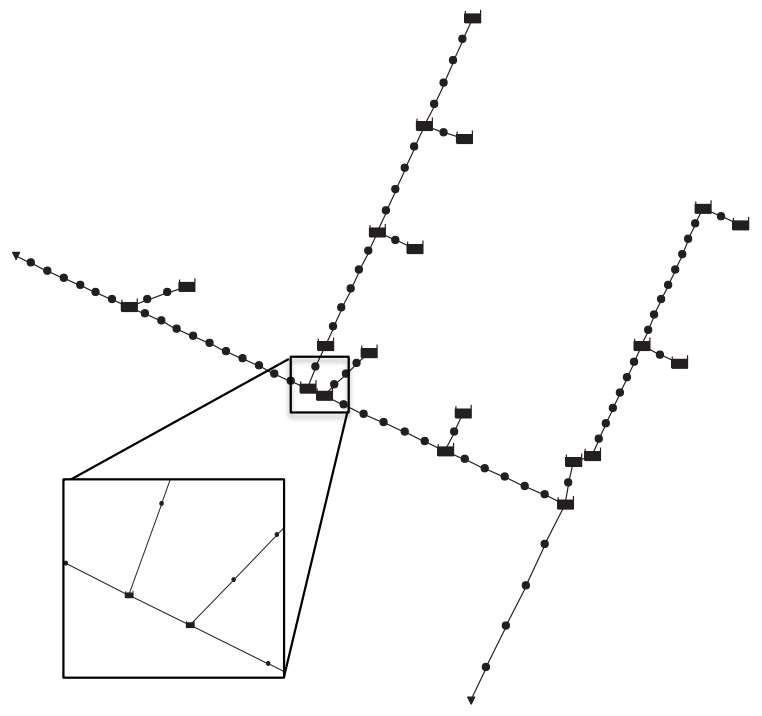

Figure 5 Alternative layout: Diameter Based (10×).

\section{Model Performance Evaluation}

The first model performance evaluation was a graphical analysis between observed and simulated data. According to ASCE (1993), a graphical analysis is necessary as a first step to evaluate the 
performance of a model since it provides a general overview of the performance and an overall feeling for model capabilities. The timing of water arrival at PV07, water oscillations, water rise and decline, peak value, and curve fitting to observed data were some of the key aspects analyzed for each approach. ASCE (1993) recommends these features as the main objectives of evaluating graphically single-events simulations.

The statistical analysis was performed using two metrics. The first was the coefficient of determination $r^{2}$. This metric is the square of the Pearson product-moment correlation co-efficient and it describes the proportion of the total variance in measured data explained by the model, ranging from 0 to 1 , with higher values indicating better agreement (Legates and McCabe 1999). The coefficient of determination is given by Equation 6:

$$
r^{2}=\left(\frac{\sum_{i=1}^{n}\left(Y_{i}^{\text {obs }}-\overline{Y^{\text {obs }}}\right)\left(Y_{i}^{\text {comp }}-\overline{Y^{\text {comp }}}\right)}{\sqrt{\sum_{i=1}^{n}\left(Y_{i}^{\text {obs }}-\overline{Y^{o b s}}\right)^{2} \sum_{i=1}^{n}\left(Y_{i}^{\text {comp }}-\overline{Y^{\text {comp }}}\right)^{2}}}\right)^{2}
$$

where:

$$
\begin{aligned}
Y_{i}^{\text {obs }} & =\text { observed values of } Y, \\
Y_{i}^{\text {comp }} & =\text { computed values of } Y, \\
\overline{Y^{\text {obs }}} & =\text { mean of observed values of } Y, \text { and } \\
\overline{Y^{\text {comp }}} & =\text { mean of computed values of } Y .
\end{aligned}
$$

Nash-Sutcliffe efficiency (NSE; Nash and Sutcliffe 1970) was also selected because it represents an improvement over the coefficient of determination since it is sensitive to differences in the observed and simulated means and variances (Legates and McCabe 1999). Also, this metric is widely used by hydrologists and engineers worldwide. The NSE is defined by Equation 7:

$$
N S E=1-\left[\frac{\sum_{i=1}^{n}\left(Y_{i}^{o b s}-Y_{i}^{c o m p}\right)^{2}}{\sum_{i=1}^{n}\left(Y_{i}^{o b s}-\overline{Y^{o b s}}\right)^{2}}\right]
$$

\section{Results and Discussions}

\subsection{Field Measurements}

The upstream reservoir in the collection system was filled with water, and subsequently quickly released, for two separate experiments. The results generated from the first rapid filling event are referred to as event 1 results while the second release results are referred to as event 2 results. The measurements obtained at PV02 and PV07 for both events are shown in Figure 6.
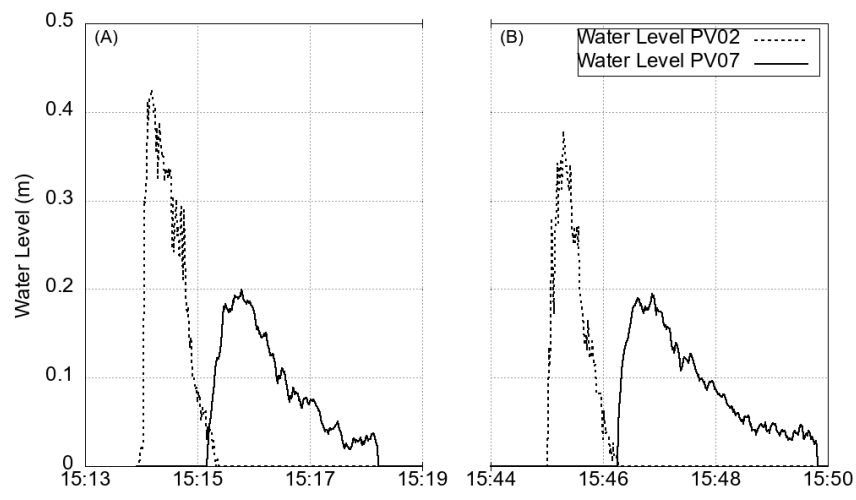

Figure 6 Field measurement results for (a) event 1 and (b) event 2 .

The results show that the general pattern of water level variation is similar for both events.

\subsection{Comparison of Field Measurements and Mod- eling Results}

\section{Traditional Approach}

Running the simulation using the traditional approach generated the results for the two events shown in Figure 7.

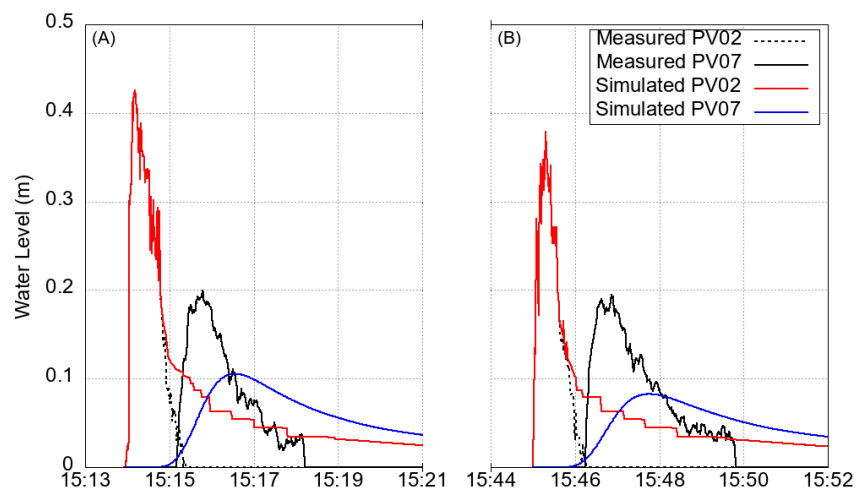

Figure 7 Results for (a) event 1 and (b) event 2 using the Traditional network layout.

The simulated results using the traditional layout for both events did not accurately represent the field data. The water level simulated at PV02 showed a recession curve that is not observed in the measured data. This layout gave an inaccurate time for the simulated water arrival at PV07 but the time when the simulated water level was more significant $(>0.01 \mathrm{~m})$ is very similar to the observed time of that occurrence. However, the model did not capture the oscillations in water level, the modeled water level rise and decrease are diffuse, and the peak is underestimated.

Table 1 compares the measured times of water level arrival and peak depth values with the simulated results for both events 
at PV07. The table also shows the continuity error and total elapsed time for this simulation.

Table 1 Traditional layout simulation summary.

\begin{tabular}{|c|c|c|c|c|c|c|}
\hline \multirow[b]{2}{*}{ Event } & \multicolumn{2}{|c|}{ Measured } & \multicolumn{2}{|c|}{ Simulated } & \multirow{2}{*}{$\begin{array}{c}\text { Continuity } \\
\text { Error }\end{array}$} & \multirow[b]{2}{*}{ Comp. Time } \\
\hline & Peak Depth & $\begin{array}{c}\text { Water Arrival } \\
\text { Time }\end{array}$ & Peak Depth & $\begin{array}{c}\text { Water Arrival } \\
\text { Time }\end{array}$ & & \\
\hline 1 & $0.20 \mathrm{~m}$ & $15: 15: 11$ & $0.10 \mathrm{~m}$ & $15: 14: 31$ & $-4.57 \%$ & $21 \mathrm{~s}$ \\
\hline 2 & $0.19 \mathrm{~m}$ & $15: 46: 16$ & $0.08 \mathrm{~m}$ & $15: 45: 33$ & $13.1 \%$ & $24 \mathrm{~s}$ \\
\hline
\end{tabular}

The maximum peak depth difference between observed and simulated values is $0.10 \mathrm{~m}$ for event 1 and $0.11 \mathrm{~m}$ for event 2. The simulated time of water arrival at PV07 is earlier by $40 \mathrm{~s}$ for event 1 and by $43 \mathrm{~s}$ for event 2 . However, as stated above, for the arrival time when the water level is significant (i.e. $>0.01 \mathrm{~m}$ ) these differences are reduced to $1 \mathrm{~s}$ for both events. The continuity errors for both events show that the sum of the all outflow from the network divided by the sum of all of the inflow to the network is not in balance. The time for the computation was in the order of just a few seconds.

\section{Alternative Layout: Regular Interval (10 Dummy Junctions)}

\section{Discretization}

Running the simulation with 10 dummy junctions at regular intervals generated the results for the two events shown in Figure 8.
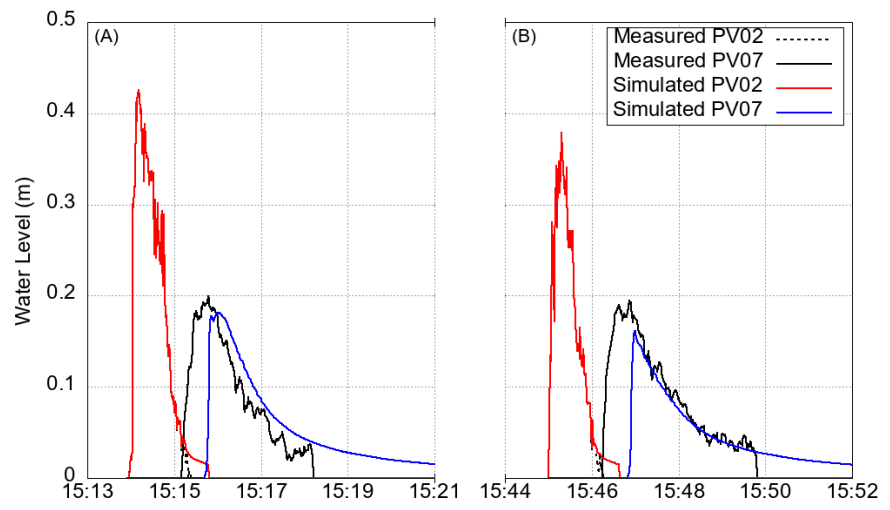

Figure 8 Results for (a) event 1 and (b) event 2 using Regular Interval for 10 dummy junctions.

This layout showed better results for the simulation at PV02. Compared to the traditional layout, this alternative layout showed a small difference between measured and simulated values at the recession of the inflow data. The simulations using this approach captured and the water level oscillations at PV07 and represented them better than the traditional approach. A sharper rise in water level at PV07 was also captured using this layout. However, the timing of water arrival is still incorrect.

Table 2 compares the measured times of water level arrival and peak depth values with the simulated results for both events at PV07 and gives the continuity error and total elapsed time for this layout.
Table 2 Alternative layout: Regular Interval simulation summary.

\begin{tabular}{|c|c|c|c|c|c|c|}
\hline \multirow[b]{2}{*}{ Event } & \multicolumn{2}{|c|}{ Measured } & \multicolumn{2}{|c|}{ Simulated } & \multirow{2}{*}{$\begin{array}{c}\text { Continuity } \\
\text { Error }\end{array}$} & \multirow[b]{2}{*}{ Comp. Time } \\
\hline & Peak Depth & $\begin{array}{c}\text { Water Arrival } \\
\text { Time }\end{array}$ & Peak Depth & $\begin{array}{c}\text { Water Arrival } \\
\text { Time }\end{array}$ & & \\
\hline 1 & $0.20 \mathrm{~m}$ & $15: 15: 11$ & $0.18 \mathrm{~m}$ & $15: 15: 38$ & $0 \%$ & $190 \mathrm{~s}$ \\
\hline 2 & $0.19 \mathrm{~m}$ & $15: 46: 16$ & $0.16 \mathrm{~m}$ & $15: 46: 45$ & $0 \%$ & $205 \mathrm{~s}$ \\
\hline
\end{tabular}

The simulation underestimated the peak depth by $0.02 \mathrm{~m}$ for event 1 and $0.03 \mathrm{~m}$ for event 2 . The simulated time of water arrival at PV07 was later by $27 \mathrm{~s}$ for event 1 and by $29 \mathrm{~s}$ for event 2. The sum of all outflow from the network divided by the sum of all inflow to the network is in balance because the simulation returned a $0 \%$ continuity error. However, the computation time for the simulation was much longer than for the traditional layout.

Alternative Layout: Fixed Interval (1 m-3 m) Discretization The next simulation used the fixed intervals. The results for both events are shown in Figure 9.
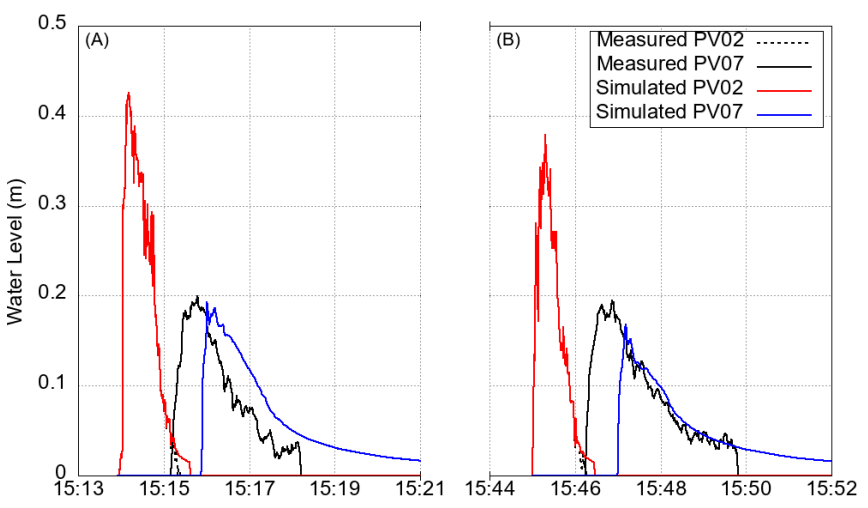

Figure 9 Results for (a) event 1 and (b) event 2 using Fixed Interval.

As did the previous approach, this alternative layout showed improved results compared to the traditional layout for the water rise and decrease and peak values at PV07. At PV02, a slight reduction of the inflow recession was seen compared to the previous approach. However, water oscillations at the peak region were more evident than in the previous regular intervals approach.

Table 3 compares the measured times of water level arrival and peak depth values with the simulated results for both events at PV07 and shows the continuity error and total elapsed time for this approach.

Table 3 Alternative layout: Fixed Intervals simulation summary.

\begin{tabular}{|c|c|c|c|c|c|c|}
\hline \multirow[b]{2}{*}{ Event } & \multicolumn{2}{|c|}{ Measured } & \multicolumn{2}{|c|}{ Simulated } & \multirow{2}{*}{$\begin{array}{c}\text { Continuity } \\
\text { Error }\end{array}$} & \multirow[b]{2}{*}{ Comp. Time } \\
\hline & Peak Depth & $\begin{array}{c}\text { Water Arrival } \\
\text { Time }\end{array}$ & Peak Depth & $\begin{array}{c}\text { Water Arrival } \\
\text { Time }\end{array}$ & & \\
\hline 1 & $0.20 \mathrm{~m}$ & $15: 15: 11$ & $0.19 \mathrm{~m}$ & $15: 15: 51$ & $0 \%$ & $267 s$ \\
\hline 2 & $0.19 \mathrm{~m}$ & $15: 46: 16$ & $0.17 \mathrm{~m}$ & $15: 46: 58$ & $0 \%$ & $288 \mathrm{~s}$ \\
\hline
\end{tabular}


This approach decreased the difference between observed and simulated peak values. For event 1 the difference is 0.01 $\mathrm{m}$ and for event 2 the difference is $0.02 \mathrm{~m}$. The timing of water arrival is less precise when compared to the traditional and the previous layouts. It is later by $40 \mathrm{~s}$ for event 1 and $42 \mathrm{~s}$ for event 2 . The continuity error is also $0 \%$ but the computation time for this simulation is greater than for the other layouts.

\section{Alternative Layout: Diameter Based (10×) Discretization}

The last alternative layout proposed in this work was that based on conduit diameter. Simulation results for this approach are shown in Figure 10.

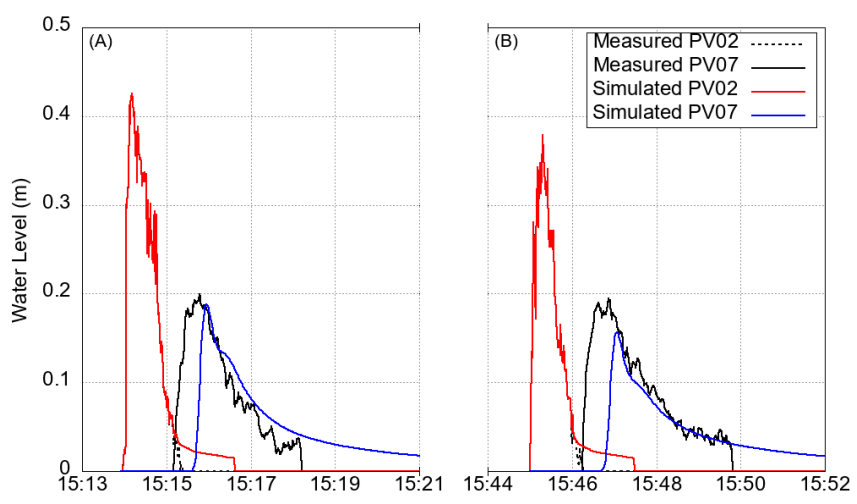

Figure 10 Results for (a) event 1 and (b) event 2 using the

Diameter Based approach.

The results obtained by this approach were similar to those obtained for the regular interval simulation, with slight differences in the peak regions and recession curves. Similar to the previous alternative layouts proposed in this work, the results were better than the traditional layout when analysing the water rise and decrease, peak values at PV07 and the recession curve of the inflow at PV02.

Table 4 compares the measured times of water level arrival and peak depth values with the simulated results for both events at PV07 and the continuity error and total elapsed time for this approach.

Table 4 Alternative layout: Diameter Based simulation summary.

\begin{tabular}{|c|c|c|c|c|c|c|}
\hline \multirow[b]{2}{*}{ Event } & \multicolumn{2}{|c|}{ Measured } & \multicolumn{2}{|c|}{ Simulated } & \multirow{2}{*}{$\begin{array}{c}\text { Continuity } \\
\text { Error }\end{array}$} & \multirow[b]{2}{*}{ Comp. Time } \\
\hline & Peak Depth & $\begin{array}{c}\text { Water Arrival } \\
\text { Time }\end{array}$ & Peak Depth & $\begin{array}{l}\text { Water Arrival } \\
\text { Time }\end{array}$ & & \\
\hline 1 & $0.20 \mathrm{~m}$ & 15:15:11 & $0.19 \mathrm{~m}$ & $15: 15: 28$ & $0 \%$ & $74 \mathrm{~s}$ \\
\hline 2 & $0.19 \mathrm{~m}$ & $15: 46: 16$ & $0.16 \mathrm{~m}$ & $15: 46: 33$ & $0 \%$ & $92 \mathrm{~s}$ \\
\hline
\end{tabular}

The results generated by this approach showed a difference in measured and simulated peak values of $0.01 \mathrm{~m}$ for event 1 and $0.03 \mathrm{~m}$ for event 2 . The time of water arrival was later by $17 \mathrm{~s}$ for both events. As for all alternative layouts, the continuity error was $0 \%$. However, the computation time for this layout was smaller than for the other alternative layouts.

\section{Statistical Analysis}

The metrics used to evaluate the model performance for event 1 are shown in Table 5.

Table 5 Model performance for event 1.

\begin{tabular}{cccccccc}
\hline \multicolumn{2}{c}{ Traditional } & \multicolumn{2}{c}{ Regular Interval } & \multicolumn{2}{c}{ Fixed Interval } & \multicolumn{2}{c}{ Diameter Based } \\
PV02 & PV07 & PV02 & PV07 & PV02 & PV07 & PV02 & PV07 \\
\hline \multicolumn{8}{c}{ Coefficient of determination $\left(r^{2}\right)$} \\
0.96 & 0.18 & 1.00 & 0.32 & 1.00 & 0.15 & 0.99 & 0.34 \\
\multicolumn{8}{c}{ Nash Sutcliffe Efficiency (NSE) } \\
0.81 & 0.16 & 1.00 & 0.21 & 1.00 & -0.15 & 0.99 & 0.28 \\
\hline
\end{tabular}

Analysing the statistical results for PV02, the coefficient of determination was very close to 1 for each approach, showing good agreement between observed and simulated data. However, a smaller value of the coefficient of determination (0.96) is found when using the SWMM traditional approach. NSE accentuated the indication of disagreement between the observed and simulated data at PV02, with an NSE value of 0.81 for the Traditional approach. The alternative approaches were very close to 1 , showing a very good agreement in this metric.

For PV07, the Fixed Interval had the lowest value of coefficient of determination (0.15). The Regular Interval (0.32) and Diameter Based (0.34) approaches showed improvements when compared to the Traditional approach (0.18). NSE values were similar to the coefficient of determination, having a value 0.16 for the Traditional, 0.21 for the Regular Interval, -0.15 for the Fixed Interval, and 0.28 for the Diameter Based. Considering both the coefficient of determination and NSE, the model did not generate good results. The reason for this is the incorrect timing of simulated water arrival at PV07, impairing in the metrics results.

The statistics used to evaluate the model performance for event 2 are shown in the Table 6.

Table 6 Model performance for event 2

\begin{tabular}{cccccccc}
\hline \multicolumn{2}{c}{ Traditional } & \multicolumn{2}{c}{ Regular Interval } & \multicolumn{2}{c}{ Fixed Interval } & \multicolumn{2}{c}{ Diameter Based } \\
PV02 & PV07 & PV02 & PV07 & PV02 & PV07 & PV02 & PV07 \\
\hline \multicolumn{8}{c}{ Coefficient of determination $\left(r^{2}\right)$} \\
0.96 & 0.19 & 1.00 & 0.26 & 1.00 & 0.13 & 0.99 & 0.29 \\
& \multicolumn{7}{c}{ Nash Sutcliffe Efficiency (NSE) } \\
0.77 & 0.10 & 1.00 & 0.07 & 1.00 & -0.14 & 0.99 & 0.13 \\
\hline
\end{tabular}

For event 2 the statistical results at PV02 were similar to event 1 , with the smaller value of coefficient of determination for the Traditional approach (0.96) and the alternative approaches showing values very close to 1 . Similar to event 1 , the NSE results for event 2 emphasised these results.

At PV07, the Fixed Interval also showed the smaller value (0.13) when the others, including the Traditional Approach, showed higher values of the coefficient of determination. Analysis of NSE shows that only the Diameter Based approach had the NSE value (0.13) greater than the Traditional approach (0.10). 
We think that these poor statistical results are related to the timing of water arrival at PV07. Since the collection system used in this field investigation is aged and poorly maintained, some unaccounted storage, detritus, or illegal connections may not be perfectly represented by the SWMM simulation. To verify this, we adjusted the simulation results at PV07 to match the exact timing of measured water arrival at PV07. This generated the following statistics (Table 7) for event 1.

Table 7 Model performance for event 1 with timing adjustment.

\begin{tabular}{cccccccc}
\hline \multicolumn{2}{c}{ Traditional } & \multicolumn{3}{c}{ Regular Interval } & \multicolumn{2}{c}{ Fixed Interval } & \multicolumn{2}{c}{ Diameter Based } \\
PV02 & PV07 & PV02 & PV07 & PV02 & PV07 & PV02 & PV07 \\
\hline \multicolumn{8}{c}{ Coefficient of determination $\left(r^{2}\right)$} \\
0.96 & 0.02 & 1.00 & 0.91 & 1.00 & 0.92 & 0.99 & 0.77 \\
0.81 & -0.65 & 1.00 & 0.90 & 1.00 & 0.92 & 0.99 & 0.76 \\
\hline
\end{tabular}

The results obtained were significantly improved. Analysing the coefficient of determination shows that the results are $>0.90$ for all alternative approaches except the Diameter Based at PV07 (0.77). The Traditional approach at PV07 had the least value of 0.02 . The NSE results were also good for the majority of alterna-tive approaches, having its least value for the Diameter Based approach at PV07 (0.76). The Traditional approach at PV07 also had the least value $(-0.65)$ for the simulations.

Table 8 shows the results for event 2 adjusting the timing. It is possible to assert that the results were improved, showing very good coefficient of determination for PV02 (>0.95) for all approaches and good results for PV07 using the alternative approaches. As in the great majority of cases, PV02 simulated using the Traditional approach showed the least value (0.01) of the coefficient of determination. In all cases, the NSE emphasised the results obtained by the coefficient of determination.

Table 8 Model performance for event 2 with timing adjustment.

\begin{tabular}{cccccccc}
\hline \multicolumn{2}{c}{ Traditional } & \multicolumn{2}{c}{ Regular Interval } & \multicolumn{2}{c}{ Fixed Interval } & \multicolumn{2}{c}{ Diameter Based } \\
PV02 & PV07 & PV02 & PV07 & PV02 & PV07 & PV02 & PV07 \\
\hline \multicolumn{8}{c}{ Coefficient of determination $\left(r^{2}\right)$} \\
0.96 & 0.01 & 1.00 & 0.88 & 1.00 & 0.94 & 0.99 & 0.68 \\
0.77 & -0.60 & 1.00 & 0.71 & 1.00 & 0.80 & 0.99 & 0.53 \\
\hline
\end{tabular}

As for event 1, the results for event 2 were improved, showing very good coefficient of determination for PV02 (>0.95) for all approaches and good results for PV07 using the alternative approaches. As in the great majority of cases, PV02 simulated using the Traditional approach showed the least value (0.01) of the coefficient of determination. In all cases, the NSE emphasised the results obtained by the coefficient of determination.

\subsection{Evaluation of Flow Profiles}

A visual analysis of the SWMM flow profile behaviour was performed for both events. The results shown in this section are for event 1 at time 15:14:10 in the conduit between PV02 and PV03. When analysing the traditional layout behaviour (Figure 11), details of the wave generated by the rapid filling were not captured, and a simple flow wedge is shown due to the lack of spatial discretization.

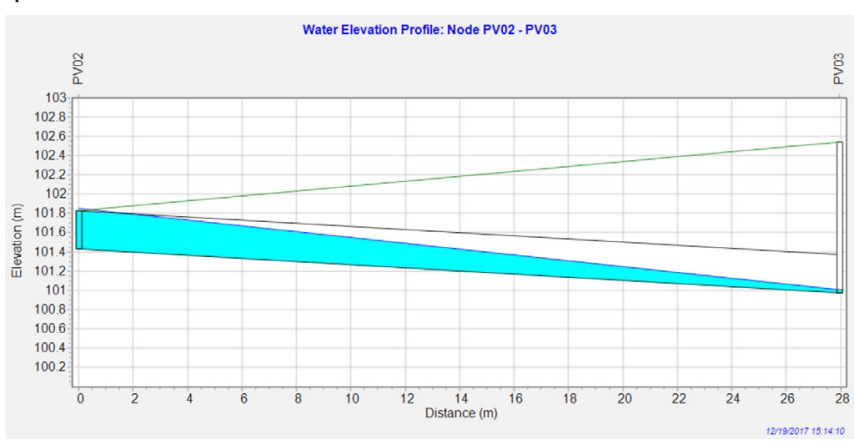

Figure 11 Flow profile of the Traditional approach.

Analysis of the behaviour of the Regular Intervals alternative layout (Figure 12) shows that the wave formed by the rapid inflow into the system was more accurately represented. However, occasional instabilities in the flow profile were detected at the dummy junctions when the water level reached the conduit crown.

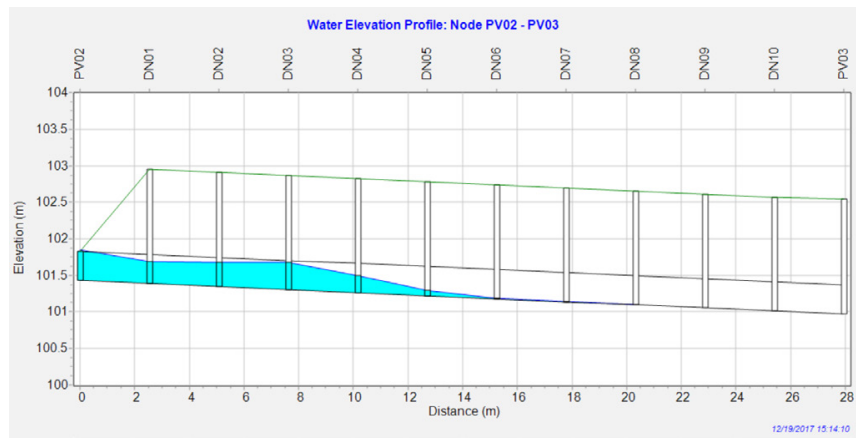

Figure 12 Flow profile of the Regular Interval approach.

The behaviour of the other alternative approaches was very similar to the Regular Intervals, showing occasional instabilities at the dummy junctions and identifying the wave generated by the rapid inflow. Since the general characteristics of these alternative approaches are similar, they will not be discussed (for brevity).

\section{Conclusions}

Modeling highly dynamic flows conditions in collection systems is very challenging. The accuracy of SWMM link-node solution to represent these situations is uncertain. Therefore, a field investigation was conducted to obtain data of rapid inflows in a collection system. The traditional layout proposed in the SWMM User's Manual was not capable of properly simulating the water level variation during rapid filling. However, adding the conceptual spatial discretization proposed in this paper significantly improved the SWMM modeling of extreme inflows compared to the traditional layout.

Three alternative model layouts using spatial discretization were evaluated. First, a regular interval discretization was constructed by placing 10 dummy junctions between the risers. 
Second, a fixed interval discretization was constructed by limiting the discretization length to a minimum length of $1 \mathrm{~m}$ and maximum of $3 \mathrm{~m}$. A third alternative layout, diameter based, was created using $10 \times$ the diameter of each conduit link as the discretization length.

All approaches showed different results at the inlet (PV02). The traditional layout simulation was the one that produced most disagreement between the observed and simulated data. All the alternative layouts gave satisfactory results at this node. The reason for this is that the PV02 results using a traditional SWMM link-node approach are affected by only one downstream junction. This situation causes some sort of water storage in the conduit that affects the upstream node and is reflected in the continuity error (more than $\pm 4.5 \%$ ). When using spatial discret-ization, as in the alternative layouts, this situation does not occur ( $0 \%$ continuity error). At the other monitored riser (PV07), not all approaches predicted the correct water arrival time. However, when using artificial spatial discretization significant improve-ments are achieved in terms of water rise and decrease, water peak level, and continuity error, although the statistical indicators did not show good results. Thus, based on the findings of this experiment, the authors recommend the use of additional spatial discretization when modeling highly dynamic flows in SWMM, es-pecially the alternative approach based on 10x conduit diameter, because it requires less computational effort when compared to other alternative approaches to improve the results.

It is also important to note that the physical drainage system used in this experiment is aged and poorly maintained. The system can be damaged at various points or have detritus in its interior that can cause some unaccounted losses or storage that are not characterized in the SWMM models. Furthermore, there may be some illegal and unaccounted connections that can delay water arrival or cause significant variations in water level. The authors believe that this may be the main reason for the small values of $r^{2}$ and NSE.

In conclusion, the use of artificial spatial discretization in links leads to improvements in modeling extreme inflows by SWMM. These improvements lead to a more precise unsteady flow modeling using a well-known and globally established model. However, using artificial spatial discretization in SWMM significantly increases the computational time to perform a single simulation, but this additional time is comparable to other models that are able to represent transient flows in stormwater systems. For this reason, the authors recommend setting up the model with additional spatial discretization only when highly dynamic situations are expected. Also, the selected routing time step for the performed simulations was very small and variations of the time step were not thoroughly investigated. In some situations, the number of dummy nodes and the magnitude of the inflow may require smaller or variable time steps for a precise simulation, depending on a careful analysis by the user.

Moving forward, perhaps a new system must be used for validation in new studies. Moreover, since a new SWMM release (5.1.013) which has the Preissmann Slot option is avail- able, the impact of using the Preissmann slot along with spatial discretization should also be evaluated. Other needs to be studied are the effect of discretization in other system geometries, including conditions with multiple time-varying inflow hydrographs.

\section{Acknowledgment}

We would like to acknowledge the support of CAPES, which provides support for the first author, and UFSM, which permitted the exchange of knowledge between Brazil and the United States and provided all the needs for the field experiment.

\section{References}

Arduino. 2018. "Introduction". http://www.arduino.cc/en/Guide/Introduction.

ASCE. 1993. "Criteria for Evaluation of Watershed Models." Journal of Irrigation and Drainage Engineering 119 (3): 429-42.

Camorani, G., A. Castellarin and A. Brath. 2005. “Effects of LandUse Changes on the Hydrologic Response of Reclamation Systems." Physics and Chemistry of the Earth 30:561-74. https://doi.org/10.1016/j.pce.2005.07.010

Chow, M. F., Z. Yusop and M. E. Toriman. 2012.“Modelling Runoff Quantity and Quality in Tropical Urban Catchments Using Storm Water Management Model." International Journal of Environmental Science and Technology 12 (9): 737-748. https://doi.org/10.1007/s13762-012-0092-0

DHI. 2017. Mouse Pipe Flow - Reference Manual. http://manuals.mikepoweredbydhi.help/2017/Cities/ MOUSEPipeFlowReference.pdf

EPA. 2017. SWMM. Washington, DC: U.S. Environmental Protection Agency. https://www.epa.gov/water-research/storm-watermanagement-model-swmm

Guizani, M., J. G. Vasconcelos, S. J. Wright and K. Maalel. 2006. “Investigation of Rapid Filling of Empty Pipes" Journal of Water Management Modeling 14: R225-20. doi: 10.14796/JWMM.R225-20.

Legates, D. R. and G. J. McCabe Jr. 1999. "Evaluating the Use of 'Goodness-of-Fit' Measures in Hydrologic and Hydroclimatic Model Validation." Water Resources Research 35 (1): 233-41.

Nash, E. and V. Sutcliffe. 1970. "River Flow Forecasting Through Conceptual Models Part I: A Discussion of Principles." Journal of Hydrology 10:282-90.

Niazi, M., C. Nietch, M. Maghrebi, N. Jackson, B. R. Bennett, M. Tryby and A. Massoudieh. 2017. "Storm Water Management Model: Performance Review and Gap Analysis." Journal of Sustainable Water in the Built Environment 3 (2). https://doi.org/10.1061/JSWBAY.0000817

Obropta, C. C. and J. S. Kardos. 2007. "Review of Urban Stormwater Quality Models: Deterministic, Stochastic, and Hybrid Approaches." Journal of the American Water Resources 
Association 43 (6): 1508-23.

https://doi.org/10.1111/j.1752-1688.2007.00124.x

Popescu, I. 2014. Computational Hydraulics. London: IWA Publishing.

Qin, H., Z. Li and G. Fu. 2013. "The Effects of Low Impact Development on Urban Flooding Under Different Rainfall Characteristics." Journal of Environmental Management 129:577-585. https://doi.org/10.1016/j.jenvman.2013.08.026

Ridgway, K. E. and G. Kumpula. 2008. “Surge Modeling in Sewers Using Alternative Hydraulic Software Programs" Journal of Water Management Modeling 16: R228-10. doi: 10.14796/JWMM.R228-10.

Roesner, L. A., R. E. Dickinson and J. A. Aldrich. 1988. Storm Water Management Model User's Manual, Version 4, EXTRAN Addendum. Athens, GA: U. S. Environmental Protection Agency. EPA/600/3-88/001B.

Rossman, L. A. 2006. “Storm Water Management Model Quality Assurance Report: Dynamic Wave Flow Routing." In Storm Water Management Model Quality Assurance Report,1-115. Cincinnati, OH: U.S. Environmental Protection Agency. EPA/600/R-06/097.

http://www.epa.gov/water-research/storm-water-management-model-swmm

Rossman, L. A. 2015. Storm Water Management Model User's Manual Version 5.1. Washington, DC: U.S. Environmental Protection Agency Office of Research and Development. EPA/600/R-14/413b. http://www.epa.gov/water-research/storm-water-management-model-swmm

Rossman, L. A. 2017. Storm Water Management Model Reference Manual Volume II - Hydraulics. Washington, DC: U.S. Environmental Protection Agency. https://www.epa.gov/water-research/storm-water-management-model-swmm.

Sturm T. W. 2010. Open Channel Hydraulics. Dubuque, IA: McGraw-Hill.

Temprano, J., Ó. Arango, J. Cagiao, J. Suárez and I. Tejero. 2006. "Stormwater Quality Calibration by SWMM: A Case Study in Northern Spain." Water SA, 32 (1): 55-63. https://doi.org/10.1080/09593332308618381

Tsihrintzis, V. A. and R. Hamid. 1998. "Runoff Quality Prediction from Small Urban Catchments using SWMM." Hydrological Processes 12 (June 1996): 311-29.

Vasconcelos, J. G., Y. Eldayih and J. A. Jamily. 2018. “Evaluating Storm Water Management Model Accuracy in Mixed Flows Conditions." Journal of Water Management Modeling 26: C451. doi: 10.14796/JWMM.C451.

Wylie, E. B., and V. L. Streeter. 1993. Fluid Transients in Systems. Upper Saddle River, NJ: Prentice Hall.

Zhou, F., F. E. Hicks and P. M. Steffler. 2002. "Transient Flow in a Rapidly Filling Horizontal Pipe Containing Trapped Air." Journal of Hydraulic Engineering 128 (6): 625-34. 